\title{
ASSESSMENT OF RISK FACTORS OF HYPERTENSION AMONG ADULTS RESIDING IN URBAN SLUM OF DELHI
}

\author{
SUPRIYA DWIVEDI ${ }^{1,2}$, ZAOZIANLUNGLIU GONMEI ${ }^{1,3}$, GURUDAYAL SINGH TOTEJA $^{1,4 *}$, NIDHI SRIVASTAVA ${ }^{2}$ \\ ${ }^{1}$ Division of Nutrition, Centre for Promotion of Nutrition Research and Training with Special Focus on North East, Tribal and Inaccessible \\ Population (Indian Council of Medical Research), New Delhi, India. ${ }^{2}$ Department of Biotechnology, Amity Institute of Biotechnology, Amity \\ University Uttar Pradesh, Noida, Uttar Pradesh, India. ${ }^{3}$ Department of Food and Nutrition, Amity Institute of Food Technology, Amity \\ University Uttar Pradesh, Noida, Uttar Pradesh, India. ${ }^{4}$ Department of Nutrition, Desert Medicine Research Centre (Indian Council of \\ Medical Research), Jodhpur, Rajasthan, India. Email: gstoteja@gmail.com
}

Received: 20 November 2017, Revised and Accepted: 18 December 2017

ABSTRACT

Objective: The objective of this study is to assess the risk factors of hypertension among adults residing in urban slums of West Delhi.

Methods: A cross-sectional study was carried out among adult population of 18-59 years residing in urban slums of West Delhi. Blood pressure was measured twice using digital machine (OMRON). Height, waist circumference, and hip circumference were measured, weight was taken, and body mass index (BMI) was calculated. The Joint National Committee VII criteria were used to define hypertension, and the National Cholesterol Education Program and Adult Treatment Panel-III guidelines were used to define different categories of dyslipidemia. The World Health Organization (2014) criteria were used to classify the BMI

Results: The overall prevalence of hypertension among adults ( $n=423)$ was $25.3 \%$. Among hypertensive adults, the prevalence of obesity was $22.7 \%$, while among non-hypertensives, it was $10.9 \%$. Similarly, overweight prevalence was higher (27.3\%) in hypertensive adults compared to non-hypertensive adults (20.6\%). The overall prevalence of hypercholesterolemia, hypertriglyceridemia, high-density lipoprotein-cholesterol $<40 /<50 \mathrm{mg} / \mathrm{dl}$, and low-density lipoprotein-cholesterol (LDL-C) $\geq 130$ was $19.7 \%, 33.7 \%$, 75.7\%, and $21.8 \%$, respectively. The prevalence of hypercholesterolemia, hypertriglyceridemia, and serum LDL-C $\geq 130 \mathrm{mg} / \mathrm{dl}$ was $38 \%, 50 \%$, and $32 \%$ among hypertensive adults, while among nonhypertensive adults, it was $15 \%, 29 \%$, and $19 \%$, respectively.

Conclusion: Hypertensive adults had higher BMI, serum cholesterol, triglycerides, and LDL-C compared to non-hypertensives.

Keywords: Hypertension, Dyslipidemia, Body mass index.

(C) 2018 The Authors. Published by Innovare Academic Sciences Pvt Ltd. This is an open access article under the CC BY license (http://creativecommons. org/licenses/by/4. 0/) DOI: http://dx.doi.org/10.22159/ajpcr.2018.v11i1.23755

\section{INTRODUCTION}

In India, the prevalence of non-communicable disease has increased substantially from 1990 to 2016. Around a quarter of the disabilityadjusted life years in India in 2016 is contributed by dietary risks, high systolic blood pressure, high fasting plasma glucose, high total cholesterol (TC), and high body mass index (BMI) [1].

Hypertension and dyslipidemia are two major risk factors of cardiovascular disease [2]. Trend analysis of dyslipidemia in India revealed that over a 20-year period TC, low-density lipoproteincholesterol (LDL-C), and triglyceride (TG) levels have increased among urban population in India [3]. A recent survey of the National Nutrition Monitoring Bureau Survey indicated an overall prevalence of hypertension among urban adult men and women in selected states of India as $31 \%$ and $26 \%$, respectively [4]. Recent survey of the National Family Health Survey ([NFHS] 4; 2015-2016) also indicated increased prevalence of overweight or obesity $\left(\mathrm{BMI} \geq 25.0 \mathrm{~kg} / \mathrm{m}^{2}\right)$ among adult men $(20.7 \%)$ and women $(18.6 \%)$ as compared to NFHS 3 (20052006), where prevalence of overweight or obesity was $12.6 \%$ and $9.3 \%$ among adult men and women [5].

The present study was carried out to assess the risk factors of hypertension among adults residing in slums of Delhi.

\section{METHODS}

The cross-sectional study was carried out in adult population residing in urban slums of West Delhi. A total of 423 adults aged 18-59 years were enrolled in the study. The study population belonged to low socioeconomic background and are mainly migrants from neighboring states, i.e., Uttar Pradesh and Bihar.

Of 423 adults enrolled, blood pressure was measured from 423 adults, anthropometric measurements were taken from 304 adults, and blood samples were collected in 309 adults. Blood pressure was measured twice using digital machine (OMRON) and average was taken to assess the prevalence of hypertension.

Height and weight were recorded using a calibrated anthropometric rod with a sensitivity of $0.1 \mathrm{~cm}$ and calibrated digital scale with a sensitivity of $0.1 \mathrm{~kg}$, respectively. Waist circumference (WC) and hip circumference (HC) were measured using calibrated non-stretchable fiber glass tape. BMI was calculated by dividing the body weight (in kilograms) by the square of height (in meters).

Five ml of venous blood was drawn using disposable syringe and serum was separated for estimation of lipid profile. TC, high-density lipoproteincholesterol (HDL-C), and TG were estimated by enzymatic method using fully automatic analyzer (Roche Hitachi-902). All biochemical analysis was done at a National Accreditation Board for Testing and Calibration Laboratories Accredited Laboratory, Centre for Promotion of Nutrition Research and Training with special focus on North-East, Tribal and Inaccessible Population Indian Council of Medical Research (ICMR), New Delhi. Strict internal and external quality control of sample analysis was maintained by running controls along with the samples and by participating in BIORAD, USA, external quality assurance program. 
The Joint National Committee VII criteria [6] were used to define hypertension and the National Cholesterol Education Program and Adult Treatment Panel-III guidelines [7] were used to define different categories of dyslipidemia. The World Health Organization (2014) [8] criteria were used to classify the BMI. The biochemical, anthropometric, and blood pressure data were analyzed for percent prevalence, mean, and standard deviation. The Institutional Ethical Clearance was obtained and informed consent was taken from all the study volunteers.

\section{RESULTS}

The overall prevalence of hypertension among adults $(n=423)$ was $25.3 \%$. The prevalence of hypertension was higher $(43.0 \%)$ among adults aged 46-59 years as compared to adults aged 18-45 years (19.8\%).

The mean height and weight of male adults were $161.9 \mathrm{~cm}$ and $62.1 \mathrm{~kg}$, whereas those of female adults were $149.3 \mathrm{~cm}$ and $57.1 \mathrm{~kg}$ (Table 1). The mean level of waist and HC of the male subjects was $85.7 \mathrm{~cm}$ and $89.8 \mathrm{~cm}$, respectively, while for female, the mean waist and $\mathrm{HC}$ of the females was $86.2 \mathrm{~cm}$ and $95.7 \mathrm{~cm}$, respectively. As indicated in Table 1, the mean height, weight, BMI, WC, and HC were higher among hypertensive subjects compared to non-hypertensive subjects.

Prevalence of obesity, overweight, normal BMI, and underweight was classified according to blood pressure (Table 2). Prevalence of obesity $(22.7 \%)$ and overweight $(27.3 \%)$ was higher among hypertensive subjects compared to non-hypertensive subjects, where prevalence of obesity and overweight was $10.9 \%$ and $20.6 \%$, respectively.

The overall prevalence of hypercholesterolemia $(\geq 200 \mathrm{mg} / \mathrm{dl})$, hypertriglyceridemia ( $\geq 150 \mathrm{mg} / \mathrm{dl}$ ), and hypoalphalipoproteinemia $(<40 \mathrm{mg} / \mathrm{dl}[\mathrm{M}] ;<50 \mathrm{mg} / \mathrm{dl}[\mathrm{F}])$ was $19.7 \%, 33.7 \%$, and $75.7 \%$, respectively (Table 3 ). Around $22 \%$ of adults had LDL-C $\geq 130 \mathrm{mg} / \mathrm{dl}$.
The prevalence of hypercholesterolemia and hypertriglyceridemia was higher in females $(24.2 \%$ and $40.6 \%)$ compared to males where their prevalence was $14.6 \%$ and $25.7 \%$, respectively.

Around 38\%, 50\%, and 32\% hypertensive adults had serum cholesterol $\geq 200 \mathrm{mg} / \mathrm{dl}$, serum $\mathrm{TG} \geq 150 \mathrm{mg} / \mathrm{dl}$, and serum LDL-C $\geq 130 \mathrm{mg} / \mathrm{dl}$, respectively (Table 4). The corresponding values among non-hypertensive adults were around 15\%, 29\%, and 19\%.

\section{DISCUSSION}

Our study indicated higher BMI, serum cholesterol, TGs, and LDL-C among hypertensives compared to non-hypertensives. BMI and blood pressure are reported to be positively correlated [9]. Our study also indicated a higher prevalence of obesity (22.7\%) and overweight (27.3\%) among hypertensive subjects compared to non-hypertensive subjects, where the prevalence of obesity and overweight was $10.9 \%$ and $20.6 \%$, respectively. A study using 2009-2010, NHANES data, also revealed that both BMI and WC were significant predictors of hypertension [10]. Another study carried out in Nagpur among 370 adults aged 18-40 years reported that high BMI, high waist to hip ratio, and age group of 30-40 years were found to be associated with hypertension [11].

High LDL C, low HDL-C, and high TGs are the most common type of dyslipidemia in India [3]. Trend analysis of over two decades using data of two representative cross-sectional surveys conducted among men and women aged 35-64 years, residing in urban and rural areas (survey 1 [1991-1994], and survey 2 [2010-2012]) in the National Capital Region of Delhi indicated that rapid rise in the burden of risk factors such as overweight, raised blood pressure, and raised blood glucose [12]. Indian diabetic population is also reported to have lower HDL-C and higher LDL [13].

Our study indicated high LDL-C, low HDL-C, high TGs, and high TC among $21.8 \%, 75.8 \%, 33.7 \%$, and $19.7 \%$, respectively. A multicenter

Table 1: Mean \pm SD anthropometric measurement and blood pressure of adults

\begin{tabular}{|c|c|c|c|c|c|c|c|c|c|}
\hline \multirow{2}{*}{$\begin{array}{l}\text { Anthropometric } \\
\text { measurement }\end{array}$} & \multicolumn{3}{|l|}{ All } & \multicolumn{3}{|c|}{ Hypertensive } & \multicolumn{3}{|c|}{ Non-hypertensive } \\
\hline & Male & Female & Total & Male & Female & Total & Male & Female & Total \\
\hline Height $(\mathrm{cm})$ & $161.9 \pm 6.6$ & $149.3 \pm 7.2$ & $155.6 \pm 6.9$ & $163.1 \pm 5.0$ & $150.6 \pm 6.3$ & $156.8 \pm 5.6$ & $160.8 \pm 8.2$ & $148.1 \pm 5.1$ & $154.0 \pm 6.6$ \\
\hline Weight (kg) & $62.1 \pm 9.1$ & $57.1 \pm 12.4$ & $59.6 \pm 10.7$ & $66.9 \pm 7.7$ & $60.1 \pm 13.2$ & $63.5 \pm 10.4$ & $57.4 \pm 10.5$ & $54.2 \pm 11.6$ & $55.8 \pm 11.0$ \\
\hline BMI (kg/cm2) & $23.7 \pm 3.6$ & $25.5 \pm 5.0$ & $24.6 \pm 4.3$ & $25.2 \pm 2.8$ & $26.4 \pm 5.2$ & $25.8 \pm 4.0$ & $22.3 \pm 4.5$ & $24.6 \pm 4.9$ & $23.4 \pm 4.7$ \\
\hline $\mathrm{WC}(\mathrm{cm})$ & $85.7 \pm 10.6$ & $86.2 \pm 14.0$ & $85.9 \pm 12.3$ & $90.4 \pm 8.7$ & $90.1 \pm 14.5$ & $90.2 \pm 11.6$ & $81.1 \pm 12.6$ & $82.3 \pm 13.5$ & $81.7 \pm 13.0$ \\
\hline $\mathrm{HC}(\mathrm{cm})$ & $89.8 \pm 7.3$ & $95.7 \pm 11.2$ & $92.7 \pm 9.2$ & $91.9 \pm 6.5$ & $98.5 \pm 12.3$ & $95.2 \pm 9.4$ & $87.7 \pm 8.2$ & $92.9 \pm 10.2$ & $90.3 \pm 9.2$ \\
\hline Waist to hip ratio & $0.9 \pm 0.1$ & $0.9 \pm 0.2$ & $0.9 \pm 0.1$ & $1.0 \pm 0.1$ & $0.9 \pm 0.2$ & $0.9 \pm 0.1$ & $0.9 \pm 0.1$ & $0.9 \pm 0.2$ & $0.9 \pm 0.1$ \\
\hline
\end{tabular}

SD: Standard deviation, BMI: Body mass index, WC: Waist circumference, HC: Hip circumference

Table 2: BMI according to blood pressure

\begin{tabular}{|c|c|c|c|c|c|c|}
\hline \multirow[t]{2}{*}{ BMI } & \multicolumn{3}{|c|}{ Hypertensive } & \multicolumn{3}{|c|}{ Non-hypertensive } \\
\hline & All $(n=66)$ & Male $(n=24)$ & Female $(n=42)$ & All $(n=238)$ & Male $(n=109)$ & Female $(n=129)$ \\
\hline Obese & $15(22.7)$ & $2(8.3)$ & $13(31.0)$ & $26(10.9)$ & $7(6.4)$ & 19 (14.7) \\
\hline Overweight & $18(27.3)$ & $8(33.3)$ & $10(20.6)$ & $49(20.6)$ & $14(12.8)$ & $35(27.1)$ \\
\hline Normal & $32(48.5)$ & $14(42.9)$ & $18(54.6)$ & $130(54.6)$ & $69(63.3)$ & $61(47.3)$ \\
\hline Underweight & $1(1.5)$ & $0(2.4)$ & $1(13.9)$ & $33(13.9)$ & $19(17.4)$ & $14(10.9)$ \\
\hline
\end{tabular}

Figures in parenthesis are percent prevalence. BMI: Body mass index

Table 3: Prevalence of dyslipidemia according to gender

\begin{tabular}{llllll}
\hline Type of dyslipidemia & $\mathbf{n}$ & All & n & Male & Female \\
\hline Hypercholesterolemia $(\geq 200 \mathrm{mg} / \mathrm{dl} \mathrm{mg} / \mathrm{dl})$ & 309 & $61(19.74)$ & 144 & $21(14.58)$ & 165 \\
Hypertriglyceridemia $(\geq 150 \mathrm{mg} / \mathrm{dl})$ & 309 & $104(33.66)$ & 144 & $37(25.69)$ & 165 \\
$\begin{array}{l}\text { Hypoalphalipoproteinemia }(\mathrm{HDL}<40 \mathrm{mg} / \mathrm{dl}-\mathrm{male} \\
\text { HDL }<50 \mathrm{mg} / \mathrm{dl}-\mathrm{female})\end{array}$ & 309 & $234(75.73)$ & 144 & $92(63.89)$ & 165 \\
LDL-C $(\geq 130 \mathrm{mg} / \mathrm{dl})$ & 298 & $65(21.81)$ & 129 & $28(21.71)$ & $161)$ \\
\hline
\end{tabular}

Figures in parenthesis are percent prevalence. HDL: High-density lipoprotein, LDL-C: Low-density lipoprotein-cholesterol 
Table 4: Prevalence of dyslipidemia according to blood pressure and gender

\begin{tabular}{|c|c|c|c|c|c|c|c|c|c|c|c|c|}
\hline \multirow[t]{2}{*}{ Type of dyslipidemia } & \multicolumn{6}{|c|}{ Hypertensive } & \multicolumn{6}{|c|}{ Non-hypertensive } \\
\hline & $\mathbf{n}$ & All & $\mathbf{n}$ & Male & $\mathbf{n}$ & Female & $\mathbf{n}$ & All & $\mathbf{n}$ & Male & $\mathbf{n}$ & Female \\
\hline Hypercholesterolemia ( $\geq 200$ mg/dl mg/dl) & 70 & $27(38.57)$ & 30 & $9(30.00)$ & 40 & $18(45.00)$ & 239 & $34(15.23)$ & 114 & $12(10.53)$ & 125 & $22(17.60)$ \\
\hline Hypertriglyceridemia $(\geq 150 \mathrm{mg} / \mathrm{dl})$ & 70 & $35(50.00)$ & 30 & $13(43.33)$ & 40 & $22(55.00)$ & 239 & 69 (28.87) & 114 & $24(21.05)$ & 125 & $45(36.00)$ \\
\hline $\begin{array}{l}\text { Hypoalphalipoproteinemia (HDL }<40 \mathrm{mg} / \mathrm{dl}- \\
\text { male HDL }<50 \mathrm{mg} / \mathrm{dl} \text {-female) }\end{array}$ & 70 & $48(68.57)$ & 30 & $14(46.67)$ & 40 & $34(85.00)$ & 239 & $186(77.82)$ & 114 & $78(68.42)$ & 125 & $108(86.40)$ \\
\hline LDL-C ( $\geq 130 \mathrm{mg} / \mathrm{dl})$ & 66 & $21(31.82)$ & 26 & $8(30.77)$ & 40 & $13(32.50)$ & 232 & $44(18.97)$ & 103 & $21(20.39)$ & 121 & $23(19.01)$ \\
\hline
\end{tabular}

Figures in parenthesis are percent prevalence. HDL: High-density lipoprotein, LDL-C: Low-density lipoprotein-cholesterol

study carried out by the ICMR at Ballabhgarh (Haryana), Chennai (Tamil Nadu), Dibrugarh (Assam), Delhi, Nagpur (Maharashtra), and Thiruvananthapuram (Kerala) on risk factors for non-communicable diseases reported hypercholesterolemia as $18.1 \%$ and $23.4 \%$ among males and females in slums/periurban areas [14]. Similar findings were observed in our study where $14.6 \%$ males and $24.2 \%$ females had hypercholesterolemia. Another ICMR-India Diabetes study conducted in a representative population of three states of India, i.e., Tamil Nadu, Maharashtra, and Jharkhand and one Union Territory (Chandigarh) covering a population of 213 million people using stratified multistage sampling design to recruit individuals $\geq 20$ years of age reported that $11.8 \%$ had high LDL-C levels, $72.3 \%$ had low HDL-C, $29.5 \%$ had hypertriglyceridemia, and 13.9\% had hypercholesterolemia [15].

A study carried out among 14,215 non-hypertensive male Japanese workers (age $38 \pm 9$ years) who were followed up for a median of 4 years to determine new-onset hypertension showed that elevated serum levels of TC were associated with an increased risk of hypertension [16]. Our study revealed a higher prevalence of hypercholesterolemia (38\%), hypertriglyceridemia (60\%), and high LDL-C (32\%) among hypertensive compared to non-hypertensive adults $(15 \%, 29 \%$, and $19 \%$, respectively). A study carried out among 161 adults in rural Nigeria also reported higher mean TC levels among hypertensive participants compared to non-hypertensive participants [17]. Another study carried out in Nigeria among 250 newly diagnosed hypertensive adults with age-matched controls revealed that hypertensive adults had significantly higher TC and TG [18]. A study carried out among Lebanese diabetic patients attending a tertiary healthcare clinic revealed that age older than 65 years, obesity, female gender as well as the presence of dyslipidemia are factors that were associated with hypertension prevalence [19].

\section{CONCLUSION}

Hypertensive adults had higher BMI, serum cholesterol, TGs, and LDL-C compared to non-hypertensives.

\section{REFERENCES}

1. India State-Level Disease Burden Initiative Collaborators. Nations within a Nation: Variations in Epidemiological Transition Across the States of India, 1990-2016 in the Global Burden of Disease Study. Available from: http://www.dx.doi.org/10.1016/S0140-6736(17)328040. [Last published On 2017 Nov 14].

2. Dalal JJ, Padmanabhan TN, Jain P, Patil S, Vasnawala H, Gulati A, et al. LIPITENSION: Interplay between dyslipidemia and hypertension. Indian J Endocrinol Metab 2012;16:240-5.
3. Gupta R, Rao RS, Misra A, Sharma SK. Recent trends in epidemiology of dyslipidemias in India. Indian Heart J 2017;69:382-92.

4. NNMB Technical Report 27. Diet and Nutritional Status of Urban Population in India and Prevalence of Obesity, Hypertension, Diabetes and Hyperlipidemia in Urban Men and Women; 2017.

5. National Family Health Survey 4, 2015-2016. Ministry of Health and Family Welfare. Government of India. India Fact sheet. Available from: http://www.rchiips.org/NFHS/pdf/NFHS4/India.pdf. [Last accessed on 2017 Jun 11].

6. The Seventh Report of the Joint National Committee on Prevention, Detection, Evaluation, and Treatment of High Blood Pressure. USA: National Institutes of Health; 2004.

7. National Cholesterol Education Program, ATP III Guidelines At-AGlance Quick Desk Reference. USA: National Institutes of Health National Heart, Lung, and Blood Institute; 2001.

8. WHO. Global Database on Body Mass Index. Available from: http:// www.apps.who.int/bmi/index.jsp?introPage=intro_3.html. [Last accessed on 2017 Oct 01]

9. Kanniyappan D, Kalidhas P, Aruna RM. Age, gender related prevalence of cardiovascular risk factors in overweight and obese south Indian adults. Int J Biol Med Res 2011;2:513-52.

10. Dua S, Bhuker M, Sharma P, Dhall M, Kapoor S. Body mass index relates to blood pressure among adults. N Am J Med Sci 2014;6:89-95.

11. Patil CR, Sahoo DP, Dhoble M, Kherde A, Inamdar A. Prevalence of hypertension and its associated risk factors in young adults attending a tertiary care institute of Nagpur: A cross sectional study. Int J Community Med Public Health 2017;4:3630-5.

12. Prabhakaran D, Roy A, Praveen PA, Ramakrishnan L, Gupta R, Amarchand R, et al. 20-Year Trend of Cardiovascular Disease Risk Factors: Urban and Rural National Capital Region of Delhi, India. Global Heart; 2017. (In Press).

13. Nayak BS, Bhaktha G. Inconsistent lipid profiles exhibited among the diabetic Asian Indians of India and Trinidad - A comparative study. Int J Pharm PharmSci 2016;8:60-3.

14. Shah B, Mathur P. Surveillance of cardiovascular disease risk factors in India: The need and scope. Indian J Med Res 2010;132:634-42.

15. Joshi SR, Anjana RM, Deepa M, Pradeepa R, Bhansali A, Dhandania VK, et al. Prevalence of dyslipidemia in urban and rural India: The ICMR-INDIAB study. PLoS One 2014;9:e96808.

16. Otsuka T, Takada H, Nishiyama Y, Kodani E, Saiki Y, Kato K, et al. Dyslipidemia and the risk of developing hypertension in a working-age male population. J Am Heart Assoc 2016;5:e003053.

17. Okaka EI, Eiya BO. Prevalence and pattern of dyslipidemia in a rural community in Southern Nigeria. Afr J Med Health Sci 2013;12:82-6.

18. Osuji CU, Omejua EG, Onwubuya E, Ahaneku G. Serum lipid Profile of newly diagnosed hypertensive patients in Nnewi, South-East Nigeria. Int J Hypertens 2012;2012:710486.

19. Soubra L, Nureddin H, Omar AG, Saleh M. Factors associated with hypertension prevalence and control among Lebanese Type 2 diabetic patients. Int J Pharm PharmSci 2016;8:153-9. 